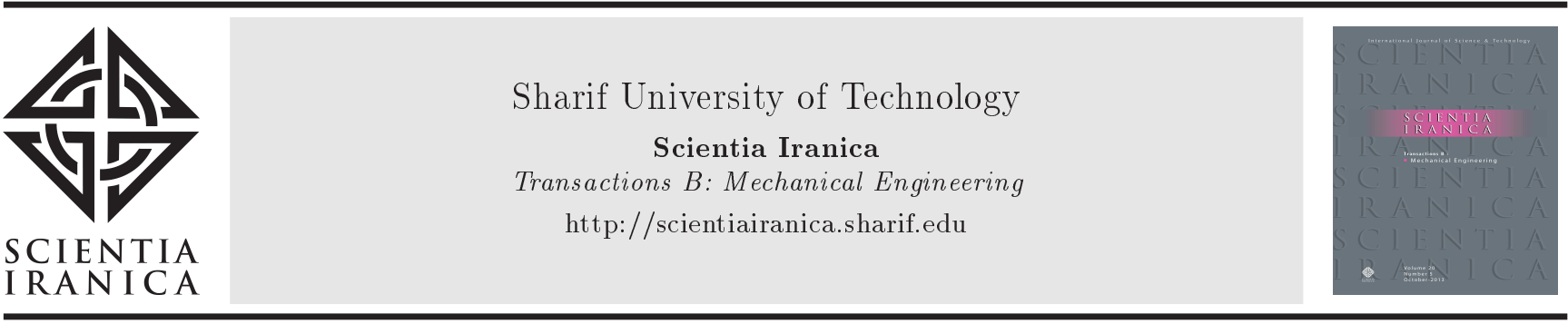

\title{
Design of optimum vibration absorbers for a bus vehicle to suppress unwanted vibrations against harmonic and random road excitations
}

\author{
A. Rezazadeh and H. Moradi* \\ Department of Mechanical Engineering, Sharif University of Technology, Tehran, P.O. Box 11155-9567, Iran.
}

Received 7 October 2018; received in revised form 22 July 2019; accepted 11 January 2020

\author{
KEYWORDS \\ Intercity bus vehicle; \\ 13-DOFs model; \\ Road roughness; \\ Harmonic \& random \\ excitations; \\ Unwanted vibrations; \\ Seat comfort; \\ Tunable vibration \\ absorbers.
}

\begin{abstract}
Unwanted vibrations of vehicles are regarded as harmful threats to human health in biomechanical and psychophysical terms. Road roughness is considered as the main cause of unwanted vibrations of bus vehicles. Vertical seat vibrations were found via simulating a 10-Degree-Of-Freedom (10-DOF) model of an intercity bus vehicle under harmonic and random excitations caused by road roughness. To suppress undesirable vibrations, mass-spring-damper passive absorbers were proposed in a 13-Degree-OfFreedom (13-DOF) model of the bus. Following the optimization of the characteristics of embedded passive absorbers under each seat and implementation of the designed absorbers, the vertical displacement amplitudes in the frequency responses of the seats were reduced, especially near the resonant frequencies of the bus. In addition, vertical displacement and acceleration amplitudes decreased in the random excitation of road roughness. According to the results, optimized mass-spring-damper absorbers were proposed as a practical solution to suppress the effects of unwanted vibration on bus vehicles.
\end{abstract}

(C) 2021 Sharif University of Technology. All rights reserved.

\section{Introduction}

Professional bus drivers are the occupants that operate vehicles for many driving hours and passengers experience unwanted vibrations mainly due to road surface excitations [1]. The unwanted vibrations of vehicles are concentrated in relatively low frequencies $(0.5-25 \mathrm{~Hz})$, exposing the driver and passengers to a condition called Whole Body Vibration (WBV) [2-4].

WBV at low frequencies can be harmful to human body since the resonant conditions have been reported to occur at natural frequencies of the viscera

\footnotetext{
*. Corresponding author. Tel.: +982166165545; Fax: +9821 66000021

E-mail address: hamedmoradi@sharif.edu, and hamedmoradi@asme.org (H. Moradi)
}

distributed in the low-frequency range of $4-10 \mathrm{~Hz}[5,6]$. Several studies have shown that WBV encompasses a wide range of health risks from biomechanical damages such as musculoskeletal, cardiovascular, nervous, gastrointestinal, etc. to psychological damages including fatigue, stress, sleep disorder, etc. [5,7-9].

Furthermore, exposure to WBV leads to Lower Back Pain (LBP) in the long run [10-12] which has been repeatedly reported as a significant health risk among professional bus drivers [13-15]. Moreover, LBP is the main reason for long sick leaves in general $[7,10,11,16]$. The exposure-response relationship between WBV and LBP has been extracted from numerous studies [17-22]; however, the mechanism by which WBV leads to the LBP has not been thoroughly identified [5,23,24].

Given that isolating the vibration of vehicles is more efficient when achieved locally than globally [25], various main strategies have been proposed in numer- 
ous studies to isolate the vibration and reduce the transmission of vibration effects on the seats. In different vehicles, these methods can include approaches such as passive control, semi-active control, and active control.

Maciejewski et al. developed a modified passive suspension system for working machine seats through modification of a viscous-elastic passive seat using air-springs and shock absorbers. In their study, the acceleration of the operator and relative displacement of seat suspension were two opposing criteria used for obtaining optimal solutions in the frequency range of $0-4 \mathrm{~Hz}[26]$.

In a study conducted by Verros et al., Single Degree of Freedom (SDOF) and 2-DOF non-linear and linear-quarter models of the vehicle were studied. These models were subjected to random road excitations to extract a methodology for optimizing the characteristics of passive suspension such as damping and stiffness [27].

Optimization of passive vibration absorbers can be challenging due to the varying conditions of a vehicle and amplification of the vibrations near the resonant frequencies [28]. Conversely, in semi-active approaches, seat suspension can be achieved sufficiently in different conditions of a vehicle [29]. Eason et al. [30] introduced a dynamic absorber with passive and semi-active tuned masses in series to reduce the vibration in a $3 \mathrm{DOF}$ system in the wider range of frequencies. Choi et al. studied the application of Magneto-Rheological (MR) dampers in vehicles such as trucks [31].

Despite their capability to optimize functionality in varying conditions, semi-active systems are known to have poor performance at relatively low frequencies [32]. Besides, ideal models of semi-active vibration isolation do not apply to actual systems due to some attributes of the real operating conditions such as hysteresis of dampers and time delays [1].

Active seat suspension, which is characterized by utilizing an external energy source, leads to a better vibration isolation performance at low frequencies [29]. Numerous studies have been conducted to incorporate this approach in vehicle suspension. Stein [33] proposed a driver's seat with an electro-pneumatic active suspension system using a pneumatic spring. Maciejewski et al. [34] designed an active seat suspension using an adaptive control strategy with high robustness against varying loads. Gan et al. [29] presented an active seat suspension system by considering the time-varying form and non-linearity of the system to isolate single and multiple frequency excitations.

Although numerous studies have considered the advantages of the active control for isolating seat vibration [35-37], an active system should technically incorporate measurements of the velocity and relative displacement, thus creating unnecessary compli- cations for the system and resulting in lower reliability. Moreover, using pneumatic systems in active control suspension may cause shortcomings such as the need to implement a large energy source to maintain the required air pressure and less reliability due to the complex controllability of the active system [38].

In some studies, the three afore-mentioned control strategies have been compared. Orečný et al. [39] reported that compared to the passive seat, the idealized semi-active control of the seat vibration isolation was improved approximately by $7 \%$. Bouazara et al. [40] performed a comparison among the passive, semi-active, and active vehicle models and concluded that the suspension was improved by approximately $50 \%$ in both active and semi-active methods.

Choosing a control strategy can become more of a trade-off problem in an actual design. While, based on the comparisons, active control seat suspension may result in better vibration cancellation, applying such systems to intercity bus seats was not feasible in commercial terms. The complexity of the system and costs of the design and operation of semi-active and active methods can be compromised with the simplicity and practicability of passive approaches at the expense of lower vibration cancellation in some cases.

In this research, the dynamics of an intercity was modeled using a 10-DOF mechanism. The vibrations of three specific seats, including the driver's seat and two passengers' seats, were evaluated by harmonic and random excitations caused by the asphalt road profile. The multiple-degree-of-freedom model of the problem facilitates a more accurate simulation of the real condition to examine the vibration transmission responses to the seats. Then, additional mass-springdamper passive absorbers were tuned for each seat with optimized characteristics to reduce the effects of vibration transmission to the seat, which would finally lead to a modified model of the bus with passive absorbers including thirteen degrees of freedom.

The efficacy of the optimized passive absorbers was then evaluated using two criteria including relative vibrations and accelerations of the seats. Implemented passive seat absorbers decrease relative vibration amplitudes in random excitations and conditions close to natural frequencies of the bus (under resonant conditions). Accelerations were also reduced in random excitations, resulting in lower force transmission to the seats.

According to this model, vibration amplitudes and accelerations in passengers' seats decreased to a greater degree than those in the driver's seat. Therefore, vibration cancellation with passive absorbers is quite a pragmatic and low-cost solution for passengers' seats on a bus and it is highly recommended to ensure greater seating and riding comfort for passengers. On the contrary, adopting the passive control strategy for 
the driver's seat is not recommended considering long working shifts and more frequent exposure to unwanted vibrations; however, using passive absorbers for the driver's seat facilitates the enhancement of vibration.

\section{Mathematical modeling of the intercity bus vehicle with vibration absorbers}

\subsection{Dynamics of the intercity bus vehicle as a 10-DOF model}

To study the dynamics and vibrations of the bus, a $10-\mathrm{DOF}$ model is used in the simulations according to the mathematical model proposed by Sekulić et al. [41]. The considered bus has stiff front rear axles attached to the vehicle body by two suspension airbags and four telescopic shock absorbers in the front axle with four suspension airbags and four telescopic shock absorbers on the rear axle. A pneumatic elastic suspension and a shock absorber are embedded in the driver's seat and the passengers' seats are stiff-suspended. The bus has two wheels on the front axle and four wheels on the rear axle, which is common in most heavy road vehicles. Furthermore, the bus is considered to be fully loaded.

Three locations considered for examining the vibration effects on the driver's and two passengers' seats are selected that represent three different parts of a bus with different experiencing modes of the transmitted vibrations in the front overhang, rear overhang, and middle part of the bus (Figure 1).

As shown in Figure 2, ten independent motions of this model comprising six vertical and four rotational motions are described as follows:

\section{Vertical motions related to:}

1. Driver's seat located in the front overhang $\left(Z_{v}\right)$;

2. Passenger's seat located in the middle of the bus $\left(Z_{P 1}\right)$;

3. Passenger's seat located in the rear overhang $\left(Z_{P 2}\right)$;
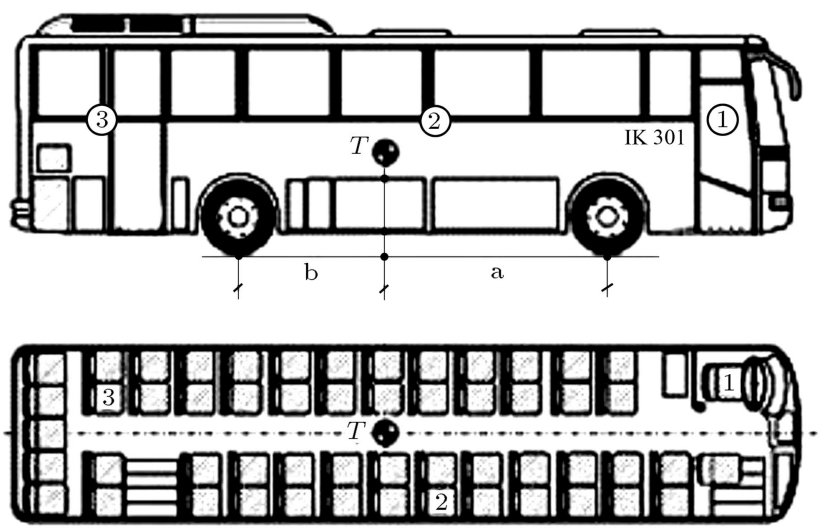

Figure 1. Schematic view of three objective seat locations for vibrational study in the bus model [41].
4. Center of gravity of the bus suspension system $(Z)$;

5. Center of gravity of the front axle $\left(Z_{1}\right)$;

6. Center of gravity of the rear axle $\left(Z_{2}\right)$.

Rotational motions describing the orientation of a Cartesian frame located at the:

7. Center of gravity of the bus suspension system about the $x$ axis $(\varphi)$;

8. Center of gravity of the bus suspension system about the $y$ axis $(\theta)$;

9. Center of gravity of the front axle about the $x 1$ axis $\left(\varphi_{1}\right)$;

10. Center of gravity of the front axle about the $x 2$ axis $\left(\varphi_{2}\right)$.

For the sake of simplicity, the model is assumed to have a constant speed movement along the $x$-axis with steady contact between the wheels and road. Front and rear axles are considered rigid bodies and the vibration characteristics of the model are linear. All sizes and vibrational characteristics of the model have been extracted from the catalog of technical data of the bus [42]. Geometrical parameters, mass properties, and oscillatory parameters of the model are given in Tables 1, 2, and 3, respectively.

By applying Lagrange's equations, the motion equations for the vertical and rotational degrees of freedom can be extracted as follows (Eqs. (1)-(10)):

For vertical motions:

$$
\begin{aligned}
& Z_{v} \text { : } \\
& m_{v} \ddot{z}_{v}+b_{s v} \dot{z}_{v}+c_{s v} z_{v}-b_{s v} \dot{z}-c_{s v} z \\
& -s_{1} b_{s v} \dot{\varphi}-s_{1} c_{s v} \varphi+s_{2} b_{s v} \dot{\theta}+s_{2} c_{s v} \theta=0 \\
& m_{p 1} \ddot{z}_{p 1}+b_{s p 1} \dot{z}_{p 1}+c_{s p 1} z_{p 1}-b_{s p 1} \dot{z}-c_{s p 1} z \\
& -s_{3} b_{s p 2} \dot{\varphi}-s_{3} c_{s p 1} \varphi-s_{4} b_{s p 1} \dot{\theta}-s_{4} c_{s p 1} \theta=0, \\
& m_{p 2} \ddot{z}_{p 2}+b_{s p 2} \dot{z}_{p 2}+c_{s p 2} z_{p 2}-b_{s p 2} \dot{z}-c_{s p 2} z \\
& -s_{3} b_{s p 2} \dot{\varphi}-s_{3} c_{s p 2} \varphi-s_{4} b_{s p 2} \dot{\theta}-s_{4} c_{s p 2} \theta=0,
\end{aligned}
$$

$Z$ :

$$
\begin{aligned}
m \ddot{z} & +\left(b_{s v}+b_{s p 1}+b_{s p 2}+2 b_{p}+2 b_{z}\right) \dot{z} \\
& +\left(c_{s v}+c_{s p 1}+c_{s p 2}+2 c_{p}+2 c_{z}\right) z \\
& +\left(s_{1} b_{s v}-s_{3} b_{s p 1}+s_{5} b_{s p 2}\right) \dot{\varphi} \\
& +\left(s_{1} c_{s v}-s_{3} c_{s p 1}+s_{5} c_{s p 2}\right) \varphi
\end{aligned}
$$


Table 1. Geometrical parameters of the model.

\begin{tabular}{|c|c|c|}
\hline Parameter & Description & Value \\
\hline$l$ & Distance from the front wheel to rear wheel & $5.65 \mathrm{~m}$ \\
\hline$a$ & Distance from the front axle to the bus center of gravity & $3.61 \mathrm{~m}$ \\
\hline$b$ & Distance from the rear axle to the bus center of gravity & $2.04 \mathrm{~m}$ \\
\hline$f_{1}$ & Distance from the front right and left wheel to the front axle center of gravity & $1.00 \mathrm{~m}$ \\
\hline$e_{1}$ & $\begin{array}{l}\text { Distance from suspension element on the front axle to the front axle center of } \\
\text { gravity and longitudinal } x \text {-axis }\end{array}$ & $0.70 \mathrm{~m}$ \\
\hline$f_{1}$ & Distance from the rear right and left wheel to the rear axle center of gravity & $1.00 \mathrm{~m}$ \\
\hline$e_{1}$ & $\begin{array}{l}\text { Distance from suspension element on the rear axle to the rear axle center of } \\
\text { gravity and longitudinal } x \text {-axis }\end{array}$ & $0.80 \mathrm{~m}$ \\
\hline$s_{1}$ & Distance from the driver seat to longitudinal $x$-axis & $0.65 \mathrm{~m}$ \\
\hline$s_{2}$ & Distance from the driver seat to transverse $y$-axis & $5.45 \mathrm{~m}$ \\
\hline$s_{3}$ & Distance from the seat of passenger 1 to longitudinal $x$-axis & $0.80 \mathrm{~m}$ \\
\hline$s_{4}$ & Distance from the seat of passenger 1 seat to transverse $y$-axis & $0.50 \mathrm{~m}$ \\
\hline$s_{5}$ & Distance from the seat of passenger 2 seat to longitudinal $x$-axis & $0.40 \mathrm{~m}$ \\
\hline$s_{6}$ & Distance from the seat of passenger 2 seat to transverse $y$-axis & $4.20 \mathrm{~m}$ \\
\hline$r_{a}$ & Distance from the rear axle suspension elements to the rear axle & $0.30 \mathrm{~m}$ \\
\hline
\end{tabular}

Table 2. Mass properties of the model.

\begin{tabular}{lll}
\hline Parameter & \multicolumn{1}{c}{ Description } & \multicolumn{1}{c}{ Value } \\
\hline$m_{v}$ & Mass of the driver and seat & $100 \mathrm{~kg}$ \\
$m_{p 1}$ & Mass of passenger 1 and seat & $90 \mathrm{~kg}$ \\
$m_{p 2}$ & Mass of passenger 2 and seat & $90 \mathrm{~kg}$ \\
$m$ & Elastic-suspended mass of the fully loaded bus & $15890 \mathrm{~kg}$ \\
$m_{p m}$ & The front axle mass & $746 \mathrm{~kg}$ \\
$m_{z m}$ & The rear axle mass & $1355 \mathrm{~kg}$ \\
$J_{x}$ & The suspended mass moment of inertia relative to the $x$-axis & $13000 \mathrm{~kg} \cdot \mathrm{m}^{2}$ \\
$J_{y}$ & The suspended mass moment of inertia relative to the $y$-axis & $150000 \mathrm{~kg} \cdot \mathrm{m}^{2}$ \\
$J_{x 1}$ & The front axle moment of inertia relative to the $x 1$ axis & $350 \mathrm{~kg} \cdot \mathrm{m}^{2}$ \\
$J_{x 2}$ & The rear axle moment of inertia relative to the $x 2$ axis & $620 \mathrm{~kg} \cdot \mathrm{m}^{2}$ \\
\hline
\end{tabular}

Table 3. Oscillatory parameters of the model.

\begin{tabular}{lll}
\hline Parameter & & \multicolumn{1}{c}{ Description } \\
\hline$c_{s v}$ & Spring stiffness of the driver seat suspension system & $10000 \mathrm{~N} / \mathrm{m}$ \\
$b_{s v}$ & Shock-absorber damping of the driver seat suspension system & $750 \mathrm{Ns} / \mathrm{m}$ \\
$c_{s p 1}, c_{s p 2}$ & Seat stiffness of the seats of passengers 1 and 2 & $40000 \mathrm{~N} / \mathrm{m}$ \\
$b_{s p 1}, b_{s p 2}$ & Damping of the seats of passengers 1 and 2 & $220 \mathrm{Ns} / \mathrm{m}$ \\
$c_{p}$ & Single air bag stiffness on the front axle & $175000 \mathrm{~N} / \mathrm{m}$ \\
$b_{1}$ & Single shock-absorber stiffness on the front axle & $20000 \mathrm{Ns} / \mathrm{m}$ \\
$b_{p}$ & Equivalent shock-absorber damping on the left and right sides of the front axle & $40000 \mathrm{Ns} / \mathrm{m}$ \\
$c_{2}$ & Single air bag stiffness on the rear axle & $200000 \mathrm{~N} / \mathrm{m}$ \\
$c_{z}$ & Equivalent air bags stiffness on the left and right sides of the rear axle & $408650 \mathrm{~N} / \mathrm{m}$ \\
$b_{2}$ & Single shock-absorber damping on the rear axle & $22500 \mathrm{Ns} / \mathrm{m}$ \\
$b_{z}$ & Equivalent shock-absorber damping on the left and the right sides of the rear axle & $45973 \mathrm{Ns} / \mathrm{m}$ \\
$c_{p p}$ & Single tire stiffness on the front and the rear axle & $1000000 \mathrm{~N} / \mathrm{m}$ \\
$c_{z p}$ & Equivalent tire stiffness on the left and right sides of the rear axle & $2000000 \mathrm{~N} / \mathrm{m}$ \\
$b_{p p}$ & Single tire damping on the front and the rear axle & $150 \mathrm{Ns} / \mathrm{m}$ \\
$b_{z p}$ & Equivalent tire damping on the left and right sides of the rear axle & $300 \mathrm{Ns} / \mathrm{m}$ \\
\hline
\end{tabular}




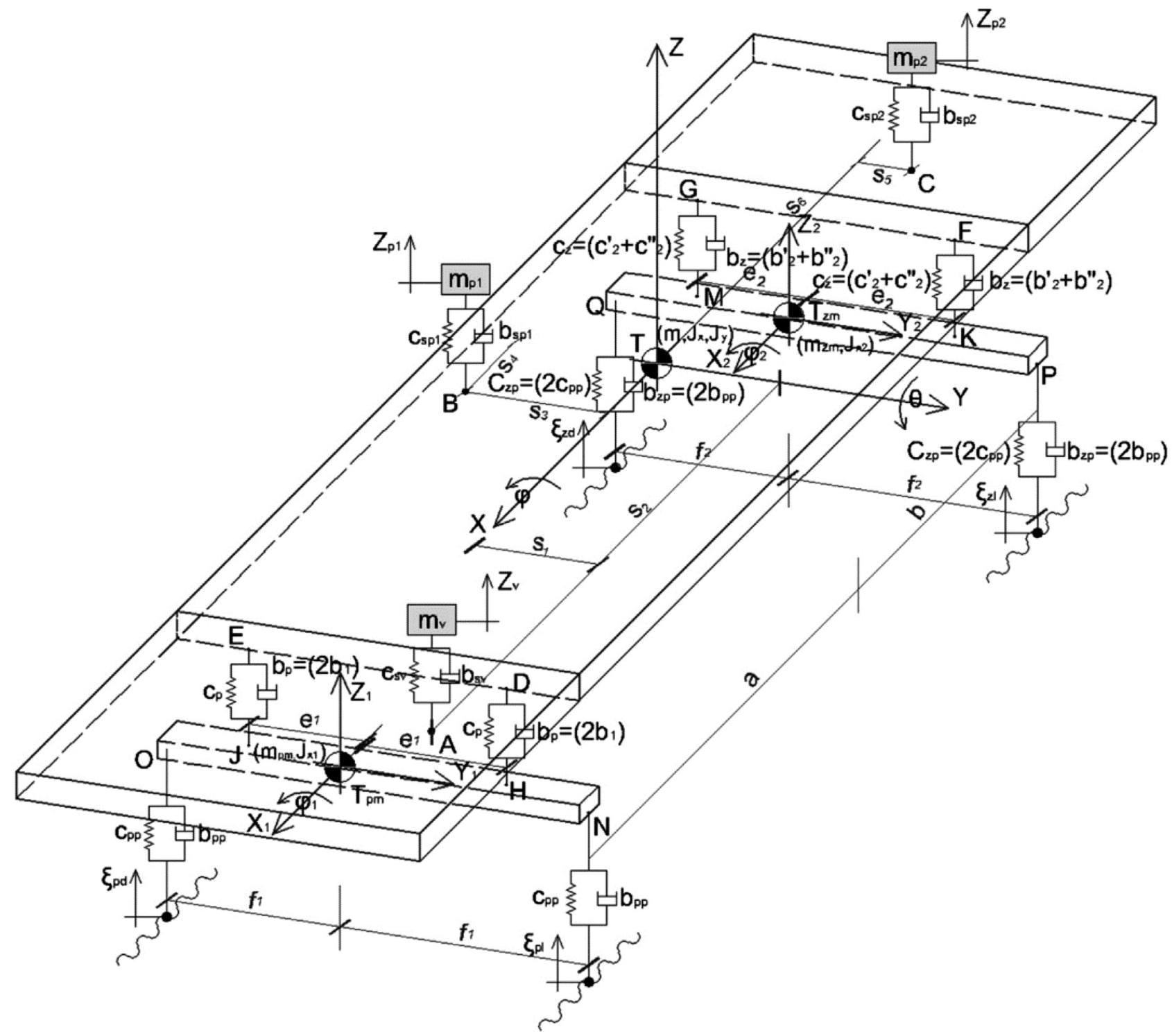

Figure 2. 10-DOF model of the bus including vertical and rotational motions [41].

$$
\begin{aligned}
& -\left(s_{2} b_{s v}+s_{4} b_{s p 1}-s_{6} b_{s p 2}+2 a b_{p}-s b b_{z}\right) \dot{\theta} \\
& -\left(s_{2} c_{s v}+s_{4} c_{s p 1}-s_{6} c_{s p 2}+2 a c_{p}-s b c_{z}\right) \theta \\
& -b_{s v} \dot{z}_{v}-c_{s v} z_{v}-b_{s p 1} \dot{z}_{p 1}-c_{s p 1} z_{p 1}-b_{s p 2} \dot{z}_{p 2} \\
& -c_{s p 2} z_{p 2}-2 b_{p} \dot{z}_{1}-2 c_{p} z_{1}-2 b_{z} \dot{z}_{2}-2 c_{z} z_{2}=0
\end{aligned}
$$

$Z_{1}$ :

$$
\begin{aligned}
m_{p m} \ddot{z}_{1} & +2\left(b_{p}+b_{p p}\right) \dot{z}_{1}+\left(c_{p}+c_{p p}\right) z_{1}-2 b_{p} \dot{z} \\
& -2 c_{p} z+2 b b_{z} \dot{\theta}+2 b c_{z} \theta=b_{p p} \dot{\varepsilon}_{p d}+c_{p p} \varepsilon_{p d} \\
& +b_{p p} \dot{\varepsilon}_{p l}+c_{p p} \varepsilon_{p l}
\end{aligned}
$$

$Z_{2}$ :

$$
\begin{aligned}
m_{z m} \ddot{z}_{2} & +2\left(b_{z}+b_{z p}\right) \dot{z}_{2}+\left(c_{z}+c_{z p}\right) z_{2}-2 b_{z} \dot{z} \\
& -2 c_{z} z+2 a b_{p} \dot{\theta}+2 a c_{p} \theta=b_{z p} \dot{\varepsilon}_{z d}+c_{z p} \varepsilon_{z d} \\
& +b_{z p} \dot{\varepsilon}_{z l}+c_{z p} \varepsilon_{z l}
\end{aligned}
$$

For rotational motions:

$\varphi:$

$$
\begin{aligned}
J_{x} \ddot{\varphi} & +\left(s_{1}^{2} b_{s v}+s_{3}^{2} b_{s p 1}+s_{5}^{2} b_{s p 2}+2 e_{1}^{2} b_{p}+2 e_{2}^{2} b_{z}\right) \dot{\varphi} \\
& +\left(s_{1}^{2} c_{s v}+s_{3}^{2} c_{s p 1}+s_{5}^{2} c_{s p 2}+2 e_{1}^{2} c_{p}+2 e_{2}^{2} b_{z}\right) \varphi \\
& -s_{1} b_{s v} \dot{z}_{v}-s_{1} c_{s v} z_{v}+s_{3} b_{s p 1} \dot{z}_{p 1}-s_{3} c_{s p 1} z_{p 1} \\
& -s_{5} b_{s p 2} \dot{z}_{p 2}-s_{5} c_{s p 2} z_{p 2}
\end{aligned}
$$


Table 4. Natural frequencies of the intercity bus vehicle.

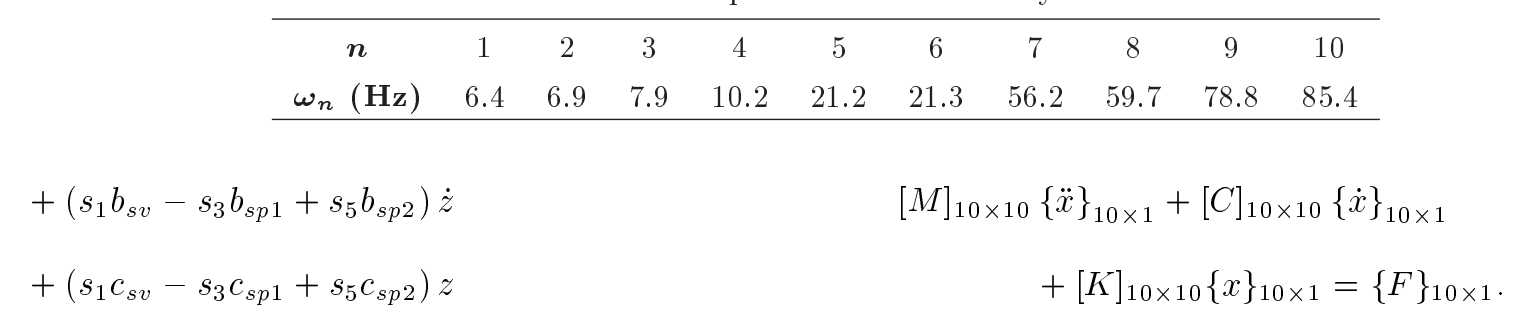

$$
\begin{aligned}
& -\left(s_{1} s_{2} b_{s v}+s_{3} s_{4} b_{s p 1}-s_{5} s_{6} b_{s p 2}\right) \dot{\theta} \\
& -\left(s_{1} s_{2} c_{s v}+s_{3} s_{4} c_{s p 1}-s_{5} s_{6} c_{s p 2}\right) \theta-2 e_{1}^{2} b_{p} \dot{\varphi}_{1} \\
& -2 e_{1}^{2} c_{p} \varphi_{1}-2 e_{2}^{2} b_{z} \dot{\varphi}_{2}-2 e_{2}^{2} c_{z} \varphi_{2}=0,
\end{aligned}
$$

$\theta:$

$$
\begin{aligned}
J_{y} \ddot{\theta}+ & \left(s_{2}^{2} b_{s v}+s_{4}^{2} b_{s p 1}+s_{6}^{2} b_{s p 2}+2 a^{2} b_{p}+2 b^{2} b_{z}\right) \dot{\theta} \\
& +\left(s_{2}^{2} c_{s v}+s_{4}^{2} c_{s p 1}+s_{6}^{2} c_{s p 2}+2 a^{2} c_{p}+2 b^{2} b_{z}\right) \theta \\
& +s_{2} b_{s v} \dot{z}_{v}+s_{2} c_{s v} z_{v}+s_{4} b_{s p 1} \dot{z}_{p 1}+s_{4} c_{s p 1} z_{p 1} \\
& -s_{6} b_{s p 2} \dot{z}_{p 2}-s_{6} c_{s p 2} z_{p 2} \\
& +\left(s_{2} b_{s v}+s_{4} b_{s p 1}-s_{6} b_{s p 2}+2 a b_{p}-2 b b_{z}\right) \dot{z} \\
& +\left(s_{2} c_{s v}+s_{4} c_{s p 1}-s_{6} c_{s p 2}+2 a c_{p}-2 b c_{z}\right) z \\
& -\left(s_{1} s_{2} b_{s v}-s_{3} s_{4} b_{s p 1}-s_{5} s_{6} b_{s p 2}\right) \dot{\varphi} \\
& -\left(s_{1} s_{2} c_{s v}-s_{3} s_{4} c_{s p 1}-s_{5} s_{6} c_{s p 2}\right) \varphi \\
& -2 a b_{p} \dot{z}_{1}-2 a c_{p} z_{1}-2 b b_{z} \dot{z}_{2}-2 b c_{z} z_{2}=0
\end{aligned}
$$

$\varphi_{1}:$

$$
\begin{aligned}
J_{x 1} \ddot{\varphi}_{1} & +2\left(e_{1}^{2} b_{p}+f_{1}^{2} b_{z p}\right) \dot{\varphi}_{2}+2\left(e_{1}^{2} c_{p}+f_{1}^{2} c_{p p}\right) \varphi_{1} \\
& -2 e_{1}^{2} b_{p} \dot{\theta}-2 e_{1}^{2} c_{p} \theta=-f_{1} b_{p p} \dot{\varepsilon}_{p d}+f_{1} c_{p p} \varepsilon_{p d} \\
& +f_{1} b_{p p} \dot{\varepsilon}_{p l}+f_{1} c_{p p} \varepsilon_{p l}
\end{aligned}
$$

$\varphi_{2}:$

$$
\begin{aligned}
J_{x 2} \ddot{\varphi}_{2} & +2\left(e_{2}^{2} b_{z}+f_{2}^{2} b_{p p}\right) \dot{\varphi}_{1}+2\left(e_{2}^{2} c_{z}+f_{2}^{2} c_{z p}\right) \varphi_{2} \\
& -2 e_{2}^{2} b_{z} \dot{\theta}-2 e_{2}^{2} c_{z} \theta=-f_{2} b_{z p} \dot{\varepsilon}_{z d}+f_{2} c_{z p} \varepsilon_{p d} \\
& +f_{1} b_{z p} \dot{\varepsilon}_{z l}+f_{1} c_{z p} \varepsilon_{z l} .
\end{aligned}
$$

After extracting a system of differential equations by Lagrange's equations for each degree of freedom, these equations can be written in the matrix form as follows:
In this matrix form, $[M]_{10 \times 10},[C]_{10 \times 10}$, and $[K]_{10 \times 10}$ are the mass, damping, and spring stiffness coefficient matrices. In addition, $\{\ddot{x}\}_{10 \times 1},\{\dot{x}\}_{10 \times 1}$, and $\{x\}_{10 \times 1}$ denote the acceleration, velocity, and displacement of the degrees of freedom. Matrix $\{F\}_{10 \times 1}$ is the external force effect, which is representative of the effect of displacement excitation due to the road surface profile in this problem. These equations can be solved in the modal space, e.g., through the Runge-Kutta numerical method. Natural frequencies of the intercity bus vehicle model are given in Table 4 .

\subsection{Dynamics of the intercity bus vehicle with vibration absorbers}

To suppress the unwanted vibrations in the bus, the passive strategy is used in this study. As shown in Figure 3, a mass-spring-damper is embedded under each seat of the model. By implementing the three vertical vibration absorbers under the driver's seat $\left(Z_{\operatorname{ex} v}\right)$ and each of two other passengers' seats $\left(Z_{\exp 1}\right.$, $\left.Z_{\text {exp } 2}\right)$, the model becomes a $13-$ DOF one.

The dynamic equations of the intercity bus with passive absorbers (as 13-DOF model) can be obtained via Lagrange's equations (Eqs. (12)-(17)). Additional terms appear in the equations due to an increase in the system's degrees of freedom. These new terms are illustrated in the following expressions (with blue color):

For vertical motions of each seat:

$$
\begin{aligned}
& Z_{v}: \\
& \quad m_{v} \ddot{z}_{v}+c_{s v} \dot{z}_{v}+k_{s v} z_{v}-c_{s v} \dot{z}-k_{s v} z-s_{1} c_{s v} \dot{\varphi}-s_{1} k_{s v} \varphi \\
& \quad+s_{2} c_{s v} \dot{\theta}+s_{2} k_{s v} \theta-c_{\mathrm{ex} v} \dot{z}_{\mathrm{ex} v}-c_{\mathrm{ex} v} k_{\mathrm{ex} v}=0
\end{aligned}
$$

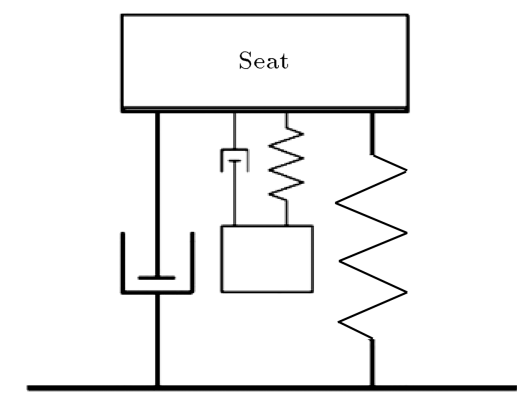

Figure 3. Schematic view of the passive absorber used for the seats. 


$$
\begin{aligned}
& Z_{p 1}: \\
& m_{p 1} \ddot{z}_{p 1}+c_{s p 1} \dot{z}_{p 1}+k_{s p 1} z_{p 1}-c_{s p 1} \dot{z}-k_{s p 1} z \\
& \quad+s_{3} c_{s p 1} \dot{\varphi}+s_{3} k_{s p 1} \varphi+s_{4} c_{s p 1} t \theta+s_{4} k_{s p 1} \theta \\
& \quad-c_{\exp 1} \dot{z}_{\operatorname{ex} p 1}-k_{\operatorname{ex} p 1} z_{\operatorname{ex} p 1}=0 \\
& Z_{p 2}: \quad \\
& m_{p 2} \ddot{z}_{p 2}+c_{s p 2} \dot{z}_{p 2}+k_{s p 2} z_{p 1}-c_{s p 2} \dot{z}-k_{s p 2} z \\
& \quad+s_{3} c_{s p 2} \dot{\varphi}+s_{3} k_{s p 2} \varphi+s_{4} c_{s p 2} \dot{\theta}+s_{4} k_{s p 2} \theta \\
& \quad-c_{\operatorname{ex} p 2} \dot{z}_{\operatorname{ex} p 2}-k_{\operatorname{ex~} p 2} z_{\operatorname{ex} p 2}=0
\end{aligned}
$$

For vertical motions of the damper under each seat:

$Z_{v}$ :

$$
\begin{gathered}
m_{\operatorname{ex} v} \ddot{z}_{\operatorname{ex} v}+c_{\operatorname{ex} v} \dot{z}_{\operatorname{ex} v}+k_{\operatorname{ex} v} z_{\operatorname{ex} v}-c_{\operatorname{ex} v} \dot{z}_{v} \\
-k_{\operatorname{ex} v} z_{v}=0,
\end{gathered}
$$

$Z_{p 1}$ :

$$
\begin{array}{r}
m_{\operatorname{ex} p 1} \ddot{z}_{\operatorname{ex} p 1}+c_{\operatorname{ex} p 1} \dot{z}_{\operatorname{ex} p 1}+k_{\operatorname{ex} p 1} z_{\operatorname{ex} p 1} \\
-c_{\operatorname{ex} p 1} \dot{z}_{p 1}-k_{\operatorname{ex} p 1} z_{p 1}=0
\end{array}
$$

$$
\begin{aligned}
& Z_{p 2}: \\
& m_{\text {ex } p 2} \ddot{z}_{\text {ex } p 2}+c_{\text {ex } p 2} \dot{z}_{\text {ex } p 2}+k_{\text {ex } p 2} z_{\operatorname{ex} p 2} \\
& -c_{\operatorname{ex} p 2} \dot{z}_{p 2}-k_{\operatorname{ex} p 2} z_{p 2}=0 .
\end{aligned}
$$

In the case of rotational motions, the equations are similar to those of the 10-DOF model (Eqs. (7)-(10)). Similar to the 10-DOFs system, differential equations can be written in the matrix form and then solved through a numerical approach; for instance consider the Runge-Kutta method in the modal space:

$$
\begin{aligned}
{[M]_{13 \times 13} } & \{\ddot{x}\}_{13 \times 1}+[C]_{13 \times 13}\{\dot{x}\}_{13 \times 1} \\
& +[K]_{13 \times 13}\{x\}_{13 \times 1}=\{F\}_{13 \times 1} .
\end{aligned}
$$

\subsection{Random model of the road profile}

Road roughness profile can be modeled as a stochastic phenomenon. The stochastic model proposed by Johannesson et al. [43] is used in this study to define the vertical displacement of a single point on the road track as follows:

$$
\xi(t)=\sum_{i=1}^{N} A_{i} \cos \left(2 \pi \Omega_{i} t+\alpha_{i}\right) .
$$

In this formulation, $\xi$ is the temporal displacement of a single point on the road described as a summation of harmonic functions with $A_{i}$ amplitudes, $\Omega_{i}$ frequencies, and $\alpha_{i}$ phase degrees which are distributed randomly in $[0-2 \pi]$. Frequencies $\left(\Omega_{i}\right)$ are calculated as follows:

$$
\begin{aligned}
& \Omega_{i}=\Omega_{l}+\left(i-\frac{1}{2}\right) \Delta \Omega, \\
& \Delta \Omega=\frac{\Omega_{u}-\Omega_{l}}{N},
\end{aligned}
$$

where $\Delta \Omega$ is the frequency step. The frequency bounds are considered to be $\Omega_{u}=50 \mathrm{~Hz}$ for the upper frequency bound and $\Omega_{l}=0.5 \mathrm{~Hz}$ for the lower frequency bound. The amplitudes $\left(A_{i}\right)$ are described as follows:

$$
A_{i}=\sqrt{2 \Phi_{\xi}\left(\Omega_{i}\right) \Delta \Omega}
$$

where $\Phi_{\xi}\left(\Omega_{i}\right)$ denotes the road roughness coefficient and is calculated in the following by means of Power Spectral Density (PSD):

$$
\Phi_{\xi}(\Omega)=V^{w-1} \Phi_{\xi}\left(\nu_{0}\right)\left(\frac{\nu_{0}}{\Omega}\right)^{w}
$$

where $\Phi_{\xi}\left(\nu_{0}\right)$ is the road roughness coefficient for the reference spatial frequency and $w$ is the fitted PSD exponent. The values for these parameters are extracted for an asphalt concrete road with a good condition as $w=2.2$ and $\Phi_{\xi}\left(\nu_{0}\right)=1.3$ for $\nu_{0}=1$. Moreover, the speed is assumed to be $V=80 \mathrm{~km} / \mathrm{h}=$ $22.23 \mathrm{~m} / \mathrm{s}$ in the simulations.

After generating a random profile for vertical displacements of two front wheels $\left(\xi_{p d}, \xi_{p l}\right)$ in the bus, the vertical displacements of the rear wheels can be calculated with a time delay of $l / V$ seconds due to the constant speed of the bus. Figure 4 presents this time shift for a randomly generated profile.
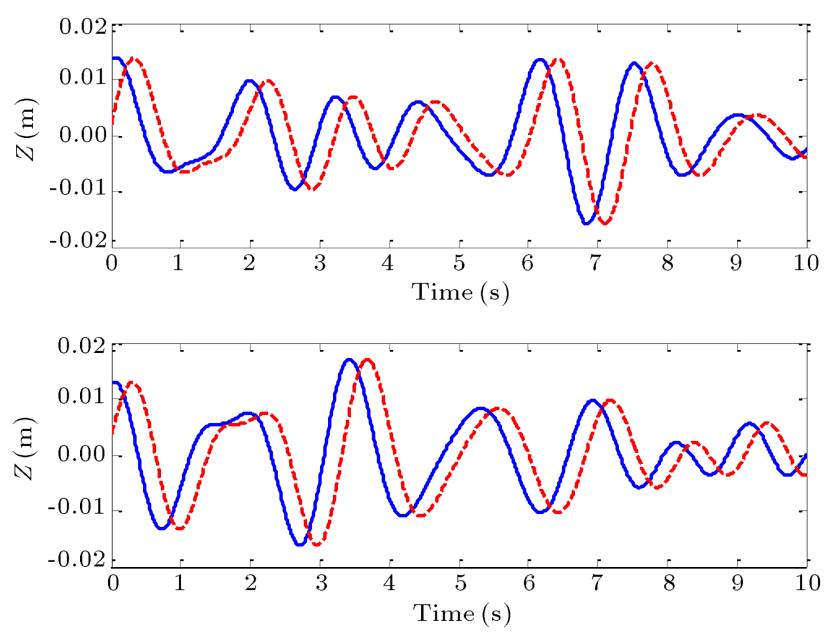

Figure 4. A random generated vertical displacement of the front wheels (-) and rear wheels (- - -) for left (upper profile) and right (lower profile) wheels sets. 


\section{Dynamic response of the intercity bus model without passive absorbers}

\subsection{Time response of the 10-DOF model under random excitation}

Dynamic study of the 3-DOF model is of significance and it includes the driver's seat located in the front overhang $\left(Z_{d}\right)$, a passenger's seat located in the middle of the bus $\left(Z_{p 1}\right)$, and a passenger's seat located in the rear overhang $\left(Z_{p 2}\right)$. The related time responses of these locations under random road excitations are shown in Figure 5.

\subsection{Time response of the 10-DOF model under harmonic excitation}

In an approach distinct from the random excitation model, harmonic excitation of the road profile can be used to extract the maximum amplitude of the displacement of each degree of freedom in the frequency domain called the frequency response of the model. In this approach, the amplitude of harmonic excitation is assumed $2 \mathrm{~cm}$, which is approximately equal to the maximum vertical displacement in the random profile of the road roughness, as shown in Figure 4.

Similar to the random profile of the road roughness, the harmonic profile is calculated for the front

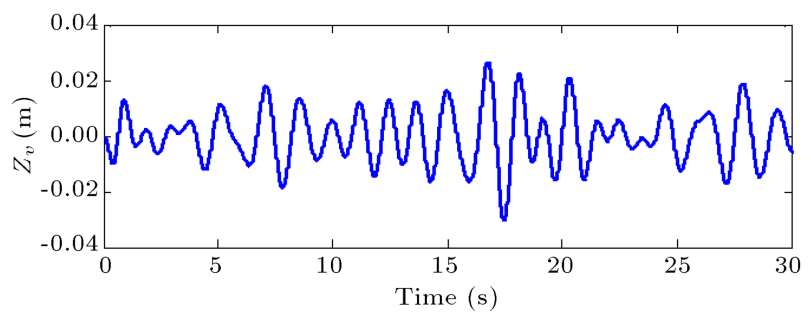

(a)

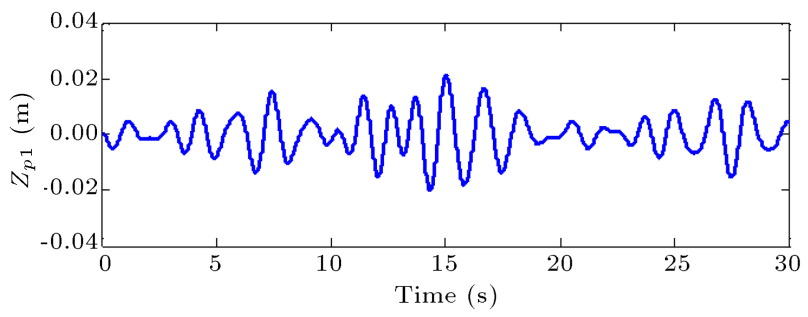

(b)

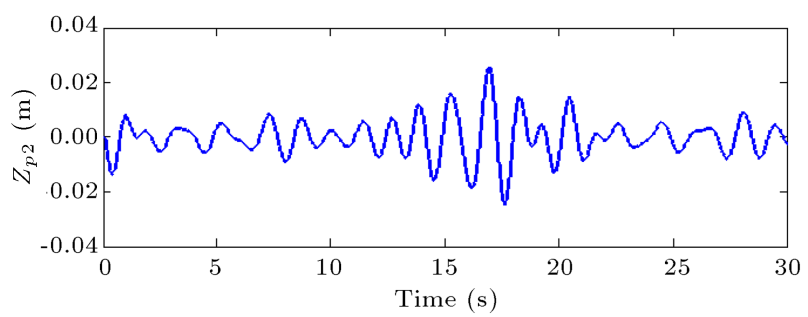

(c)

Figure 5. Vertical displacement of (a) the driver's seat, (b) the passenger's seat $P 1$ (middle seat), and (c) the passenger's seat $P 2$ (rear seat) under a random excitation of the road profile. wheels on each side of the vehicle and then, the profiles of the rear wheels are calculated with a time delay of $l / V$ seconds.

To elaborate on the effects of the designed absorbers on the vibrations of the driver and passengers, two distinct models are considered in this study. In the next simulations, one model is employed in the presence of the bus suspension parameters (damped model) and the other one is utilized in the absence of the suspension absorption parameters (undamped model), for which the absorption characteristics of the suspension system $b_{1}, b_{p}, b_{2}$, and $b_{z}$ are assumed zero.

Natural frequencies of the system are distributed in the frequency range of $0-100 \mathrm{~Hz}$, as listed in Table 4. The frequency responses of the 10-DOF model without suspension for driver's and passengers' seats are given in Figure 6.

According to Figure 6, resonance phenomenon occurs in the lower frequency range of $0-30 \mathrm{~Hz}$, as already expected. Therefore, further simulations are concentrated in this frequency domain of the system.

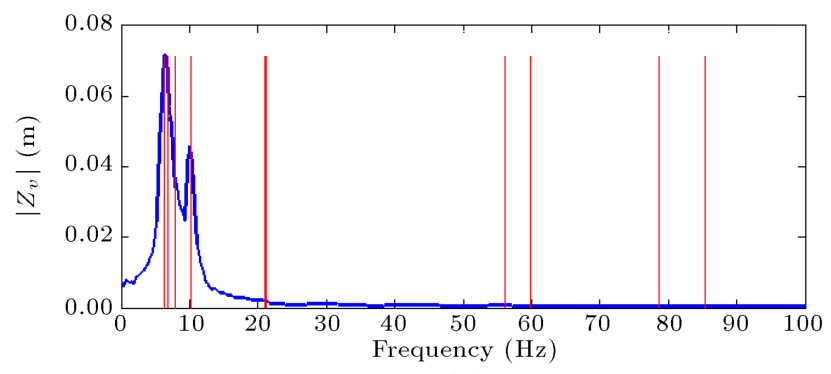

(a)

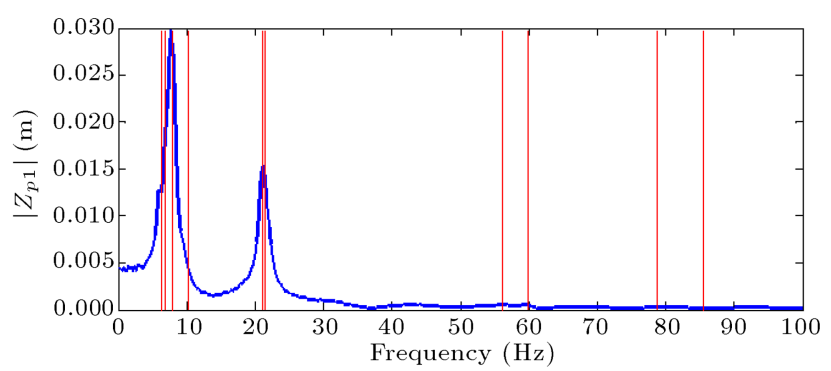

(b)

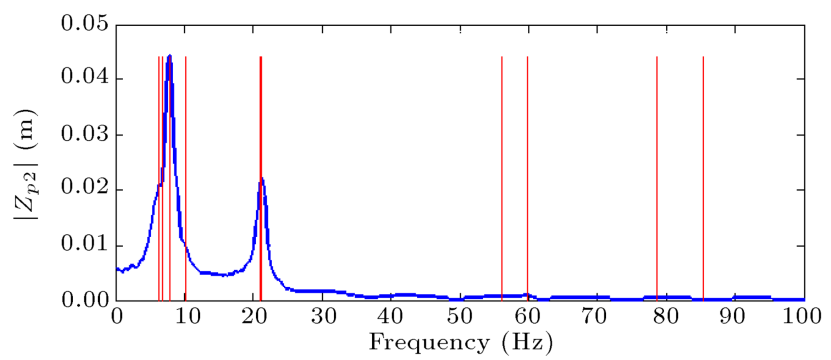

(c)

Figure 6. Frequency response of (a) the driver's seat, (b) the passenger's seat $P 1$ (middle seat), and (c) the passenger's seat $P 2$ (rear seat) in the 10 -DOF model. Vertical lines are the natural frequencies of the model. 
For the frequency range of $0-30 \mathrm{~Hz}$, a comparison between the frequency responses of the 10-DOFs model in the presence and absence of the suspension system is shown in Figure 7.

The effect of the bus suspension system is clearly shown in Figure 7 . As observed, the vibration amplitudes transmitted to the driver's and passengers' seats are reduced in the presence of the suspension system, especially near the natural frequencies where the resonance occurs. One objective of this study is to

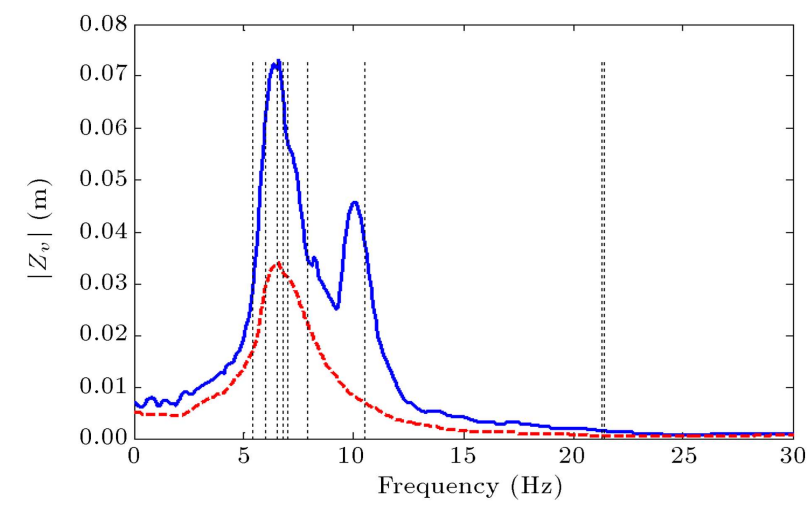

(a)

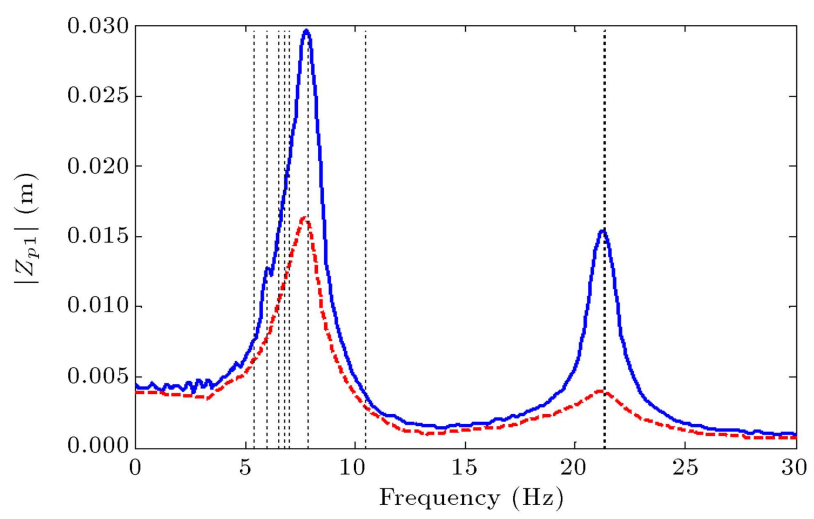

(b)

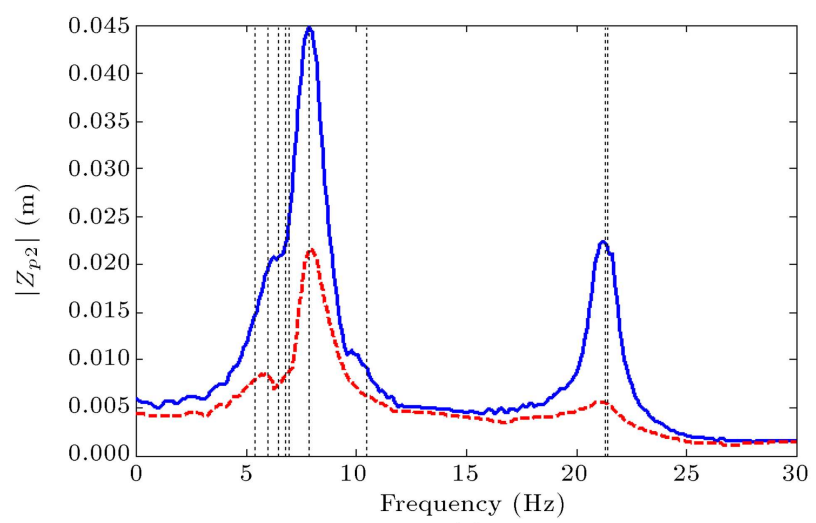

(c)

Figure 7. Frequency response of (a) the driver's seat, (b) the passenger's seat $P 1$ (middle seat), and (c) the passenger's seat $P 2$ (rear seat) in the $10-\mathrm{DOF}$ model in 0-30 $\mathrm{Hz}$ for the undamped model (-) and the damped mode (- - ). significantly reduce these amplitudes by means of the embedded mass-spring-damper absorbers to decrease the health risk and increase the comfort of the driver and passengers.

\section{Optimum design of tunable passive vibration absorbers}

The characteristics of the absorbers can be optimized through different methods. The 13-DOF dynamic model of the intercity bus including the three passivemass-spring-damper shock absorbers embedded under each of the three seats is considered. The design method used in this study is an iterative optimization method used for decreasing the vertical vibration amplitudes in the driver's and passengers' seats. Three vibrational characteristics include the mass, spring stiffness, and damping. Of note, the damping factor was not optimized since an increase in this factor would lead to a decrease in the vertical vibration amplitudes of the seats. Thus, the damping value has been set to a commonly used value of $c=10 \mathrm{Ns} / \mathrm{m}$ in practice.

The algorithm employed in this paper was first choosing initial values for mass $(m=10 \mathrm{~kg})$ and damping factors $(c=10 \mathrm{Ns} / \mathrm{m})$ for each of the three seats. Then, the maximum amplitudes of the vertical displacement for each of the three seats were recorded for different values of spring stiffness $k$ in the domain of $100-1000 \mathrm{~N} / \mathrm{m}$ by running the harmonic simulation of the undamped model in the frequency range of 0-30 Hz. The spring stiffness that resulted in the minimum vertical displacement amplitude was then reported as the optimum value of the stiffness of the absorber for each seat. Figure 8 shows the optimum point of spring stiffness for the absorbers of each of the three seats. Optimization algorithm in this stage leads to an optimum stiffness value equal to $410 \mathrm{~N} / \mathrm{m}$ for the driver's seat absorber and also, to the stiffness value of $620 \mathrm{~N} / \mathrm{m}$ for the passengers' seats.

After extracting the spring stiffness, the same optimization algorithm was performed for the mass of the absorbers to find the mass values, thus yielding the minimum vertical displacement of the seats. This iterative algorithm for optimizing stiffness and mass is practicable if the final vibrational characteristics are not significantly different from the initial values. Figure 9 demonstrates the optimum absorber mass for each of the three seats in the undamped model.

The results showed the optimum mass values of $15 \mathrm{~kg}$ and $10 \mathrm{~kg}$ for the driver's and the passengers' seat absorbers, respectively. Note that the final mass values of the absorbers are not significantly different from their initial values at $10 \mathrm{~kg}$; therefore, the iterative optimization method is practicable and the optimum values for vibrational characteristics are given as follows: 


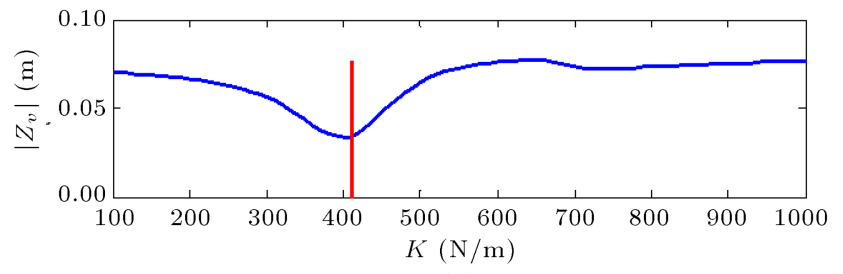

(a)

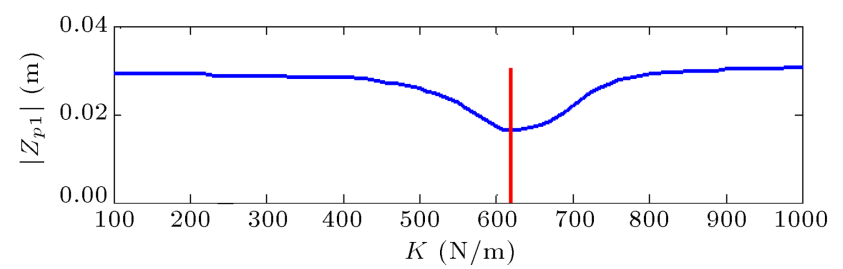

(b)

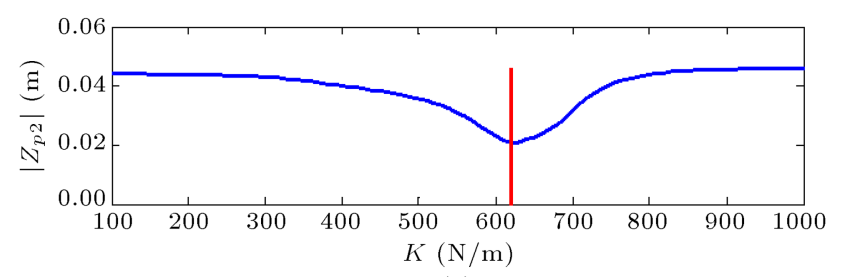

(c)

Figure 8. Maximum vertical displacement of (a) the driver's seat, (b) the passenger's seat $P 1$ (middle seat), and (c) the passenger's seat $P 2$ (rear seat) by changing the absorber's stiffness value. The vertical line shows the optimum point.

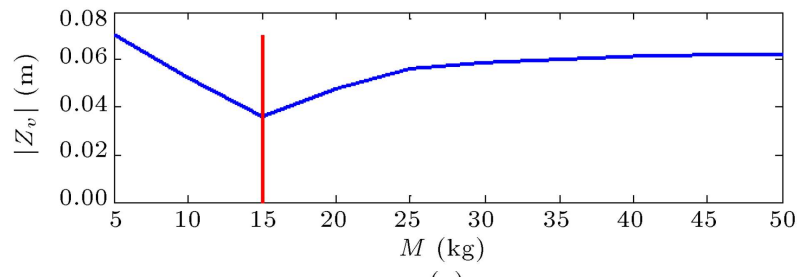

(a)

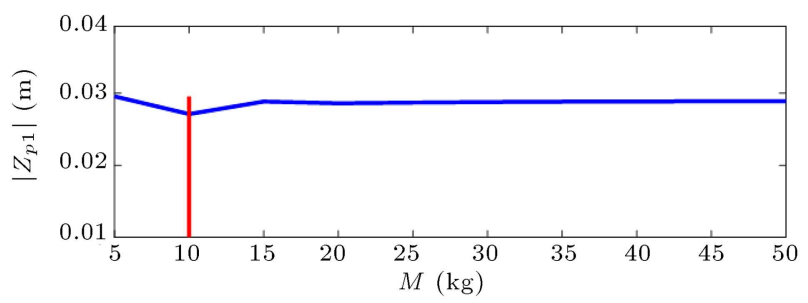

(b)

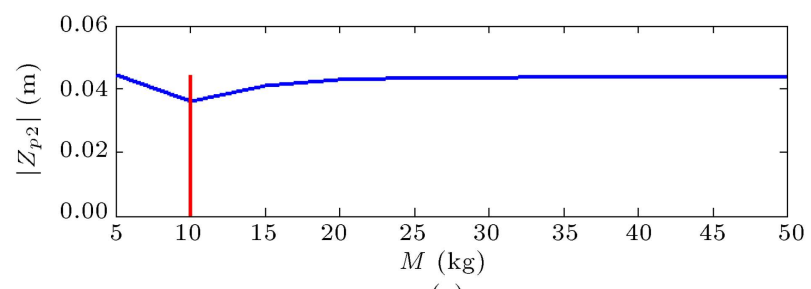

(c)

Figure 9. Maximum vertical displacement of (a) the driver's seat, (b) the passenger's seat $P 1$ (middle seat), and (c) the passenger's seat $P 2$ (rear seat) by changing the absorber's mass value. The vertical line shows the optimum point.

$$
\begin{array}{ll}
m_{\mathrm{ex} v}=15 \mathrm{~kg}, & m_{\operatorname{ex} p 1}=m_{\operatorname{ex} p 2}=10 \mathrm{~kg} \\
k_{\operatorname{ex} v}=410 \mathrm{~N} / \mathrm{m}, & k_{\operatorname{ex} p 1}=k_{\operatorname{ex} p 2}=620 \mathrm{~N} / \mathrm{m} \\
c_{\operatorname{ex} v}=c_{\operatorname{ex} p 1}=c_{\operatorname{ex} p 2}=10 \mathrm{Nsm} .
\end{array}
$$

\section{The effect of designed optimum absorbers on suppression of vibrations}

The effects of the passive absorbers embedded under the three seats can be evaluated by comparing frequency responses, time responses of the vertical displacements, and vertical accelerations of the driver's and the passengers' seats in the 10-DOF and 13-DOF models.

\subsection{The effect of designed optimum absorbers on the frequency response of the system}

By applying the optimum vibrational characteristics of the absorbers in the 13-DOF model, harmonic responses can be calculated for both damped and undamped models. Figure 10 shows the effect of embedding absorbers on the response of the undamped model. Figure 11 shows the same effect on the response of the damped model.

According to a comparison made between the model with the absorbers and that without them, in both damped and undamped cases, embedding passive absorbers under the seats reduces the maximum amplitude of seat vibrations, especially near the natural frequencies. Although the amount of vibration reduction is considerable for all seats, it has been more significant for the passengers' seats than the driver's.

\subsection{The effect of designed absorbers on time response of the system under random excitation}

The effect of implementing passive absorbers can be evaluated under random excitations caused by road roughness. Figure 12 shows the effect of the designed absorbers on suppressing the vibrations in the driver's and passengers' seats.

Of note, according to the simulation results, similar random functions of road excitation are used in the models with/without absorbers to provide the same condition, which finally resulted in a more accurate comparison. Figure 12 demonstrates a total reduction in the amplitudes of displacements in random excitation and this reduction is more significant in the passengers' seats than the driver's.

\subsection{The effect of designed absorbers on the vertical acceleration of the system under random excitation}

By calculating the second time derivative of the vertical displacements of the seats under the random exci- 


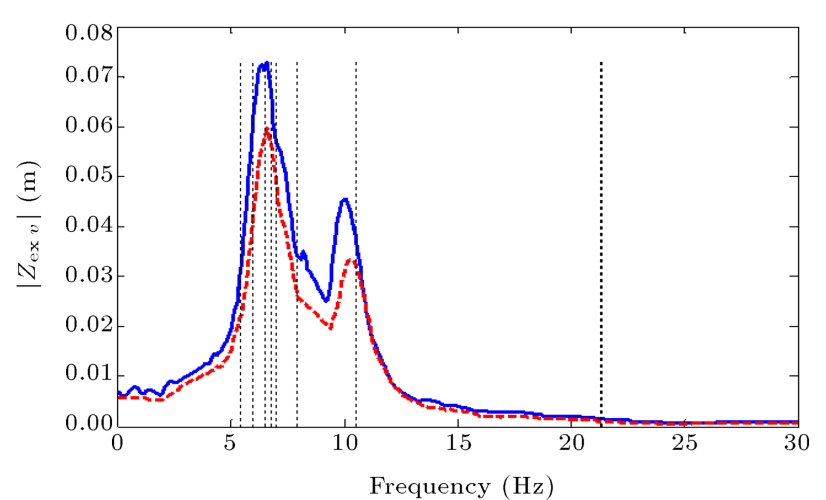

(a)

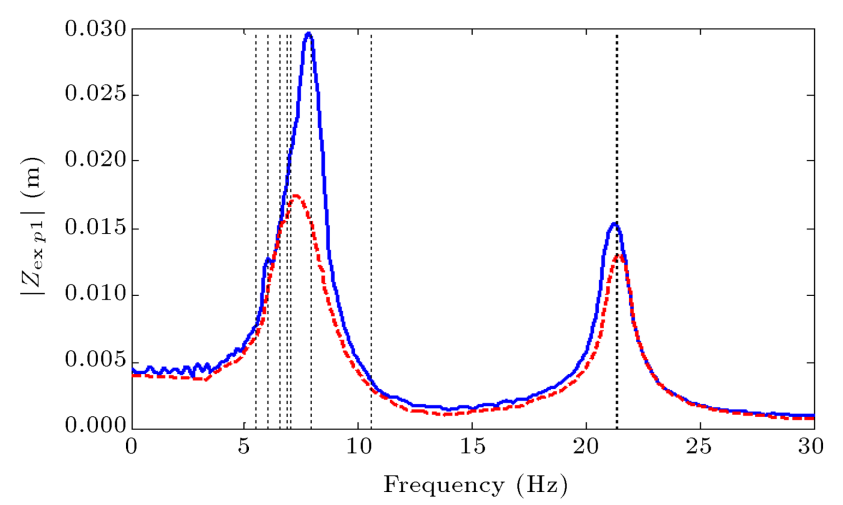

(b)

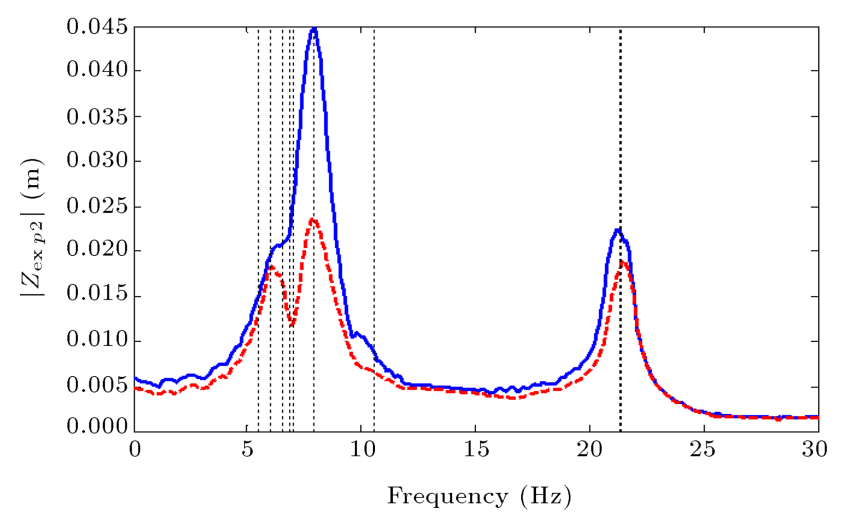

(c)

Figure 10. The effect of passive absorbers on the frequency response of (a) the driver's seat, (b) the passenger's seat $P 1$ (middle seat), and (c) the passenger's seat $P 2$ (rear seat) for undamped models without

absorber (-) and with absorber (- - ). Vertical lines are the natural frequencies of the model.

tation, vertical accelerations of the seats are calculated. Vertical acceleration corresponds to the vertical force transmitted from the seat to the human body. The comparison of the vertical acceleration of the driver's and passengers' seats in the undamped model with/without absorbers is shown in Figure 13.

After embedding the absorbers and according to these significant reductions in the amplitudes of the vertical accelerations, it is expected that lower vertical forces be transmitted from the seat to the human body.

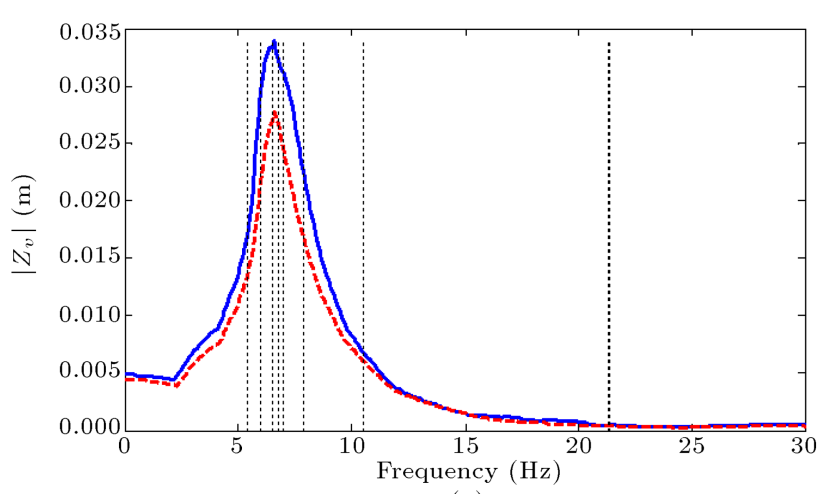

(a)

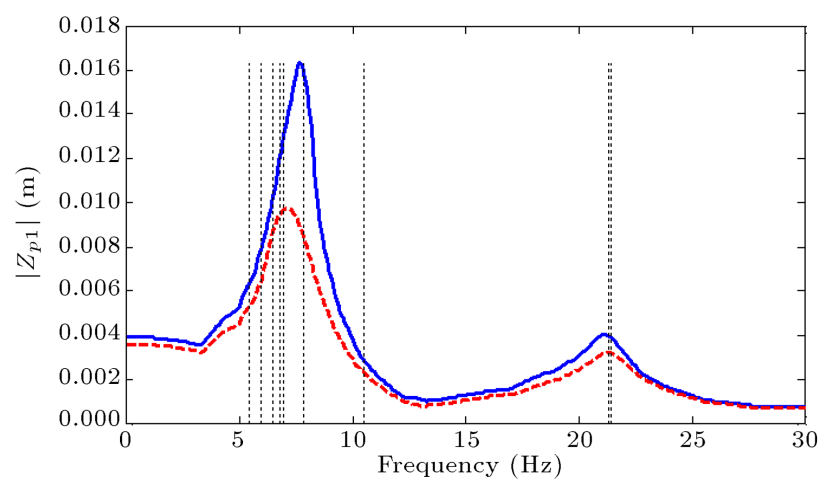

(b)

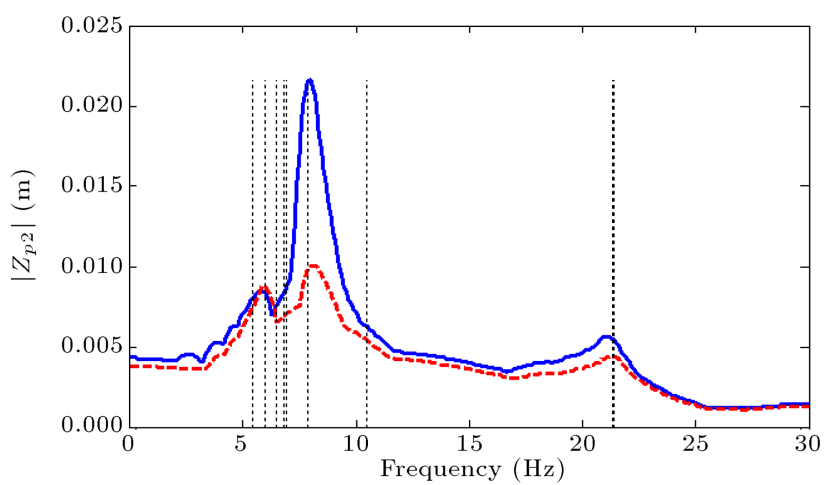

(c)

Figure 11. The effect of passive absorbers on the frequency response of (a) the driver's seat, (b) the passenger's seat $P 1$ (middle seat), and (c) the passenger's seat $P 2$ (rear seat) for damped models without absorber $(-)$ and with absorber (- - ).

\section{Conclusions}

A passive vibration isolation method was proposed in this paper to reduce the unwanted vibrational effects of road roughness on passengers of an intercity bus vehicle. To provide a more accurate simulation of real conditions and investigate the vibrations transmitted to the seats, a 10-DOF model of the bus vehicle was considered. following the inclusion of the optimized mass-spring-damper absorbers for the seats, a 13-DOF model was developed.

Implementation of the passive absorbers under the two passengers' seats and the driver's seat led to 


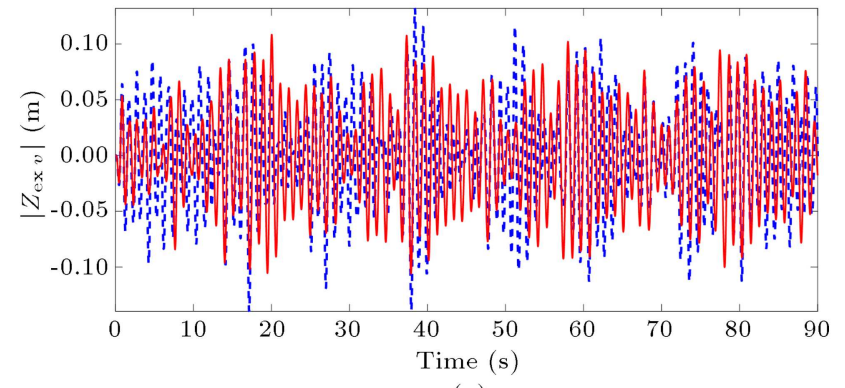

(a)

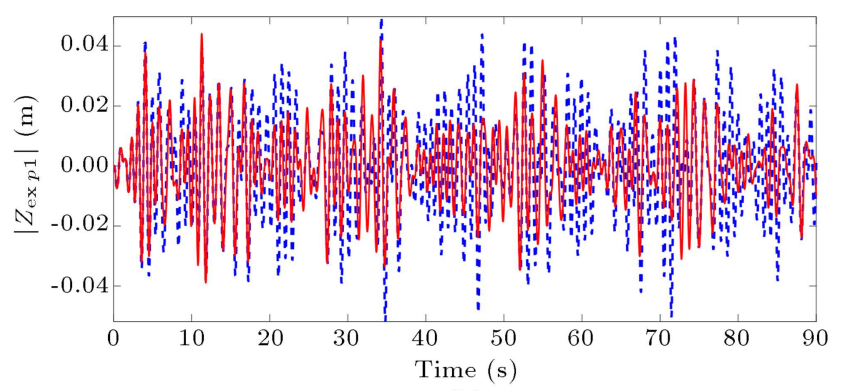

(b)

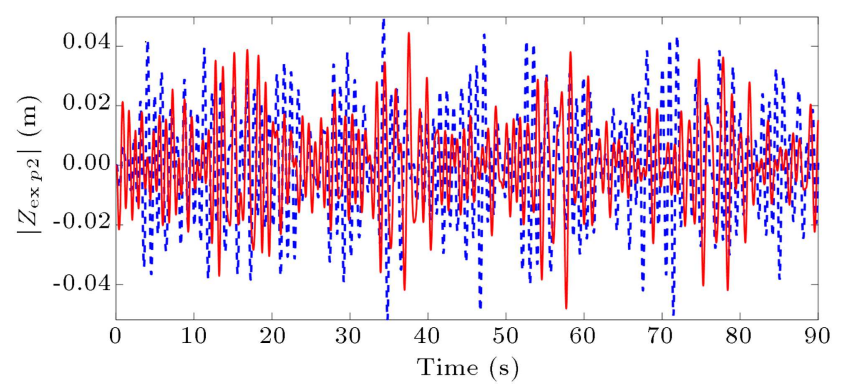

(c)

Figure 12. The effect of passive absorbers on the vertical displacement of (a) the driver's seat, (b) the passenger's seat $P 1$ (middle seat), and (c) the passenger's seat $P 2$ (rear seat) for undamped models without absorber (- - -) and with absorber $(-)$ (under random excitation).

a considerable reduction in vertical vibration amplitudes under harmonic excitation of road roughness. The amount of reduction is more significant near the natural frequencies of the vehicle where the resonance phenomenon occurs.

Under random excitations of the road roughness, it is shown that the vibration amplitudes and accelerations of the driver's and passengers' seats are also decreased by the seat passive absorbers. For both cases of the harmonic and random excitations, the reduction values are higher in the passengers' seats than the driver's seat.

According to the results, using the passive massspring-damper absorbers was suggested for suppression of vibrations in the bus vehicle. This method is also more economically pragmatic for the public transportation vehicles to enhance ride quality and comfort and reduce the health risks associated with unwanted vibrations. Lower costs of and efforts for designing

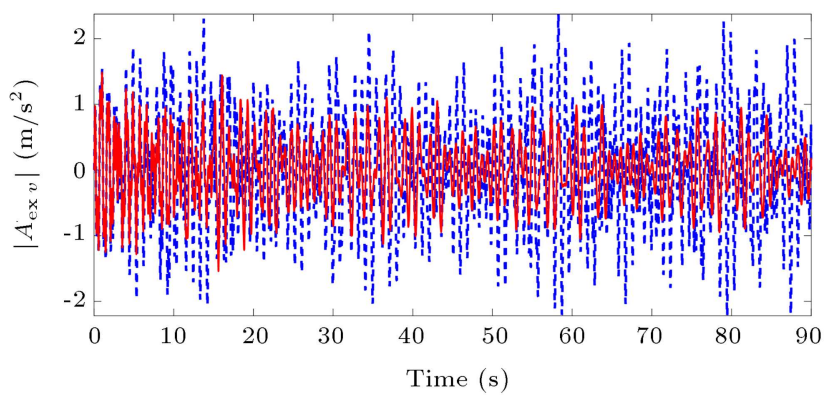

(a)

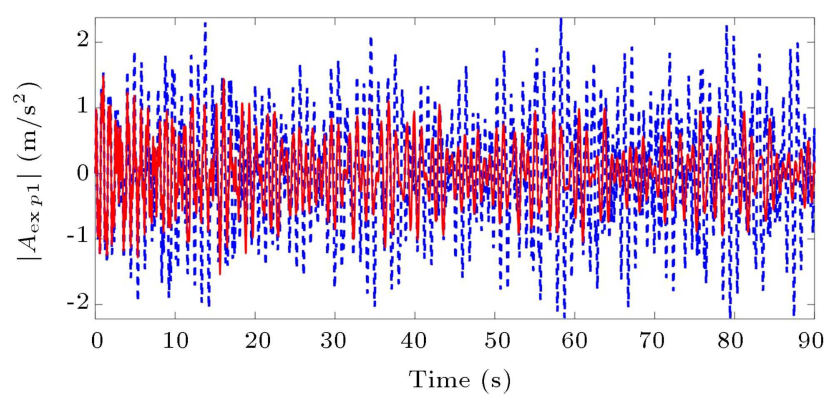

(b)

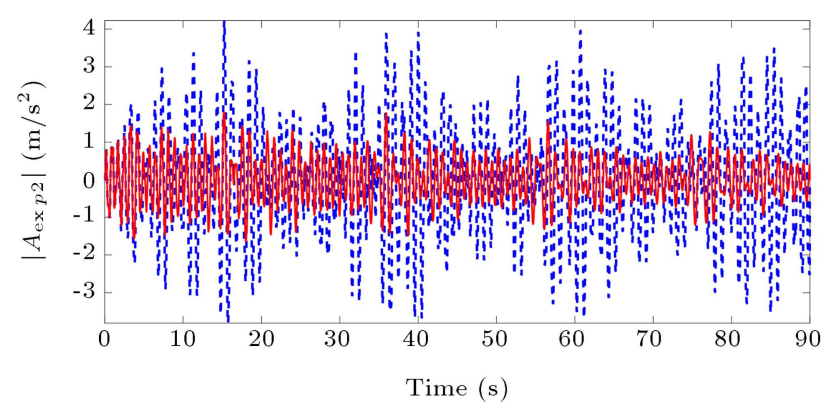

(c)

Figure 13. The effect of passive absorbers on the vertical acceleration of (a) the driver's seat, (b) the passenger's seat $P 1$ (middle seat), and (c) the passenger's seat $P 2$ (rear seat) for undamped models without absorber (- - -) and with absorber (-) (under random excitation).

and embedding the passive seat absorbers were weighed against the advantages of the semi-active and active methods for reducing the unwanted vibrations in a bus vehicle. However, according to the results, the passive method was less effective for the driver's seat than the passengers' seats). Although the vibration enhancements were made using passive absorbers for the driver's seat, it is suggested that an active or semiactive absorber be used due to its longer exposure to unwanted vibrations. In future work, we hope to enhance our modeling approach so that the mechanical characteristics of the human body can be taken into account. Mechanistic modeling of human body has been explored across many fields of study [44-46] and its detailed investigation would lead to a more solid design of vibration absorbers. 


\section{References}

1. Abakumov, A.M., Antropov, V.E., and Randi, D.G. "Electrotechnical vibration isolation system with a magnetorheological damper", In 2017 International Conference on Industrial Engineering, Applications and Manufacturing (ICIEAM), pp. 1-4. IEEE (2017).

2. Gan, Z., Hillis, A.J., and Darling, J. "Adaptive control of an active seat for occupant vibration reduction", Journal of Sound and Vibration, 349, pp. 39-55 (2015).

3. Taskin, Y., Hacioglu, Y., Ortes, F., et al. "Experimental investigation of biodynamic human body models subjected to whole-body vibration during a vehicle ride", International Journal of Occupational Safety and Ergonomics, 25(4), pp. 1-5 (2018).

4. International Organization of Standardization, ISO 7096, Earth-Moving Machinery: Laboratory Evaluation of Operator Seat Vibration, Geneva (2000).

5. International Organization for Standardization, ISO 2631-1 "Mechanical vibration and shock-evaluation of human exposure to whole body vibration - Part 1: General requirements" (1997).

6. Ciloglu, H., Alziadeh, M., Mohany, A., et al. "Assessment of the whole body vibration exposure and the dynamic seat comfort in passenger aircraft", International Journal of Industrial Ergonomics, 45, pp. 11623 (2015).

7. Alperovitch-Najenson, D., Santo, Y., Masharawi, Y., et al. "Low back pain among professional bus drivers: ergonomic and occupational-psychosocial risk factors", IMAJ, 12, pp. 26-31 (2010).

8. Bovenzi, M., Schust, M., Menzel, G., et al. "Relationships of low back outcomes to internal spinal load: a prospective cohort study of professional drivers", International Archives of Occupational and Environmental Health, 88(4), pp. 487-99 (2015).

9. Gruber, G.J. and Ziperman, H.H., Relationship Between Whole-Body Vibration and Morbidity Patterns Among Motor Coach Operators, National Institute of Occupational Safety and Health, Cincinnati, Ohio (1992).

10. Bovenzi, M. "Low back pain disorders and exposure to whole-body vibration in the workplace", Seminars in Perinatology, 20(1), pp. 38-53 (1996).

11. Magnusson, M.L., Pope, M.H., Wilder, D.G., et al. "Are occupational drivers at an increased risk for developing musculoskeletal disorders", Spine, 21(6), pp. 710-717 (1996).

12. Kim, J.H., Dennerlein, J.T., and Johnson, P.W. "The effect of a multi-axis suspension on whole body vibration exposures and physical stress in the neck and low back in agricultural tractor applications", Applied Ergonomics, 68, pp. 80-89 (2018).
13. Pope, M.H. and Novotny, J.E. "Spinal biomechanics", J. Biomech. Eng., 115, pp. 569-574 (1993).

14. Pope, M.H., Andersson, G.B.J., Frymoyer, J.W., et al., Occupational Low Back Pain: Assessment, Treatment, and Prevention, Mosby Yearbook, St. Louis, pp. 95113 (1991).

15. Webster, B.S. and Snook, S.H. "The cost of 1989 workers' compensation low back pain claims", Spine, 19, pp. 1111-1116 (1994).

16. Johanning, E. "Back disorder intervention strategies for mass transit operators exposed to whole-body vibration-comparison of two transit system approaches and practices", Journal of Sound and Vibration, 215(4), pp. 629-634 (1998).

17. Teschke, K., Nicol, A., Davies, Ju, H., et al. "Whole body vibration and back disorders among motor vehicle drivers and heavy equipment operators: a review of the scientific evidence", Report to: Workers Compensation Board of British Columbia, Vancouver, BC (1999).

18. Dreischarf, M., Shirazi-Adl, A., Arjmand, N., et al. "Estimation of loads on human lumbar spine: a review of in vivo and computational model studies", Journal of Biomechanics, 49(6), pp. 833-845 (2016).

19. Fritz, M. "Description of the relation between the forces acting in the lumbar spine and whole-body vibrations by means of transfer functions", Clinical Biomechanics, 15, pp. 234-240 (2000).

20. Krause, N., Rugulies, R., Ragland, D.R., et al. "Physical workload, ergonomic problems, and incidence of low back injury: a 7.5-year prospective study of San Francisco transit operators", American Journal of Industrial Medicine, 46(6), pp. 570-585 (2004).

21. Tiemessen, I.J.H., Hulshof, C.T.J., and Frings-Dresen, M.H.W. "Low back pain in drivers exposed to whole body vibration: analysis of a dose response pattern", Occupational and Environmental Medicine, 65, pp. 667-675 (2008).

22. National Research Council, Musculoskeletal Disorders and the Workplace, National Academy Press, Washington, DC (2001).

23. Dong, R., Krajnak, K., Wirth, O., et al., Introduction: Conference on Human Vibration, Morgantown, WV: DHHS/CDC/NIOSH, 1 (2006).

24. Wang, M., Yu, J., Liu, N., et al. "Low back pain among taxi drivers: a cross-sectional study", Occupational Medicine, 67(4), pp. 290-295 (2017).

25. Viswamurthy, S.R. and Ganguli, R. "Performance sensitivity of helicopter global and local optimal harmonic vibration controller", Computers \& Mathematics with Applications, 56(10), pp. 2468-2480 (2008).

26. Maciejewski, I., Meyer, L., and Krzyzynski, T. "Modelling and multi-criteria optimization of passive seat suspension vibro-isolating properties", Journal of Sound and Vibration, 324(3-5), pp. 520-538 (2009). 
27. Verros, G., Natsiavas, S., and Papadimitriou, C. "Design optimization of quarter-car models with passive and semi-active suspensions under random road excitation", Journal of Vibration and Control, 11, pp. 581-606 (2005).

28. Segla, S. and Trišović, N. "Optimization of semi-active seat suspension", American Journal of Mechanical Engineering, 1(7), pp. 221-225 (2013).

29. Gan, Z., Hillis, A.J., and Darling, J. "Adaptive control of an active seat for occupant vibration reduction", Journal of Sound and Vibration, 349, pp. 39-55 (2015).

30. Eason, R.P., Sun, C., Dick, A.J., and Nagarajaiah, S. "Attenuation of linear oscillator using a nonlinear and semi-active tuned mass damper in series", Journal of Sound and Vibration, 332, pp. 154-166 (2013).

31. Choi, S.B., Nam, M.H., and Lee, B.K. "Vibration control of a MR seat damper for commercial vehicles", Journal of Intelligent Material Systems and Structures, 11, pp. 936-944 (2000).

32. Chen, Y., Wickramasinghe, V., and Zimcik, D.G. "Development of adaptive helicopter seat for aircrew vibration reduction", Journal of Intelligent Material Systems and Structures, 22(5), pp. 22-489 (2011).

33. Stein, G.J. "A driver's seat with active suspension of electro-pneumatic type", Journal of Vibration and Acoustics, 119(2), pp. 230-235 (1997).

34. Maciejewski, I., Glowinski, S., and Krzyzynski, T. "Active control of a seat suspension with the system adaptation to varying load mass", Mechatronics, 24(8), pp. 1242-1253 (2014).

35. Lathkar, M.S., Shendge, P.D., and Phadke, S.B. "Active control of uncertain seat suspension system based on a state and disturbance observer", IEEE Transactions on Systems, Man, and Cybernetics: Systems, 50(3), pp. 840-850 (2017).

36. Hrovat, D. "Optimal active suspensions for $3 \mathrm{~d}$ vehicle models", Proceedings of the American Control Conference, Arizona, USA, 2, pp. 1534-1541 (1991).

37. Stein, G.J. "Results of investigation of an electropneumatic active vibration control system", Proc. Inst. Mech. Eng. Part D: J. Autom Eng., 209, pp. 227-234 (1995).

38. Sun, W., Li, J., Zhao, Y., and Gao, H. "Vibration control for active seat suspension systems via dynamic output feedback with limited frequency characteristic", Mechatronics, 21(1), pp. 250-260 (2011).

39. Orečný, M., Segl'a, Š., Huňady, R., et al. "Application of a magneto-rheological damper and a dynamic absorber for a suspension of a working machine seat", Procedia Engineering, 96, pp. 338-344 (2014).

40. Bouazara, M., Richard, M.J., and Rakheja, S. "Safety and comfort analysis of a $3-\mathrm{D}$ vehicle model with optimal non-linear active seat suspension", Journal of Terramechanics, 43(2), pp. 97-118 (2006).
41. Sekulić, D., Dedović, V., Rusov, S., et al. "Analysis of vibration effects on the comfort of intercity bus users by oscillatory model with ten degrees of freedom", Applied Mathematical Modelling, 37(18-19), pp. 86298644 (2013).

42. "Catalogue of technical data and selling prices, IKARBUS Belgrade", Factory for the Production of Buses and Special-Purpose Vehicles (2004).

43. Johannesson, P., Podgórski, K., and Rychlik, I. "Laplace distribution models for road topography and roughness", International Journal of Vehicle Performance, 3(3), pp. 224-258 (2017).

44. Kim, J.H., Abdel-Malek, K., Yang, J., and Marler, R.T. "Prediction and analysis of human motion dynamics performing various tasks", International Journal of Human Factors Modelling and Simulation, 1(1), pp. 69-94 (2006).

45. Rezazadeh, A. and Berniker, M. "Force field generalization and the internal representation of motor learning", PloS One, 14(11) (2019).

46. Fard, M.A., Tadashi, I., and Hikaru, I. "Dynamics of the head-neck complex in response to the trunk horizontal vibration: Modeling and identification", $J$. Biomech. Eng., 125(4), pp. 533-539 (2003).

\section{Biographies}

Alireza Rezazadeh graduated Sharif University of Technology in 2016 with a bachelor's degree in Mechanical Engineering. At Sharif, he focused his studies on linear systems and control theory and completed his undergraduate thesis on vibration absorption in vehicles under the supervision of Dr. Moradi. In 2019, he received his master's in Mechanical Engineering from the University of Illinois at Chicago where he worked on human motor behavior. His master's thesis was focused on motor adaptation and generalization and the underlying internal representation of motor learning.

Hamed Moradi received the BSc, Mechanical Engineering degree in solid mechanics from Amirkabir University of Technology in 2005; MSc. and PhD Mechanical Engineering in applied mechanics from Sharif University of Technology (SUT), Tehran, Iran in 2008 and 2012. Currently, he is the Associate Professor in the Department of Mechanical Engineering, Sharif University of Technology. His current research interests include the modeling of dynamic systems, application of robust, nonlinear and optimal control methods in various dynamics systems such as manufacturing, bio-engineering, thermo-fluid industrial processes and power plant engineering. Also, he investigates the analysis of nonlinear dynamics and chaos in various oscillatory phenomena and especially in two areas of thermo-fluid systems and machining chatter vibrations. 